\title{
EDITORIAL
}

\section{O renovar e o crescimento}

Tatiana Bragança de Azevedo Della Giustina ${ }^{1}$, José Hiran da Silva Gallo ${ }^{1}$, Rui Nunes ${ }^{2}$

1. Conselho Federal de Medicina, Brasília/DF, Brasil. 2. Universidade do Porto, Porto, Portugal.

A Revista Bioética, desde 2020, está se renovando de diversas formas, e, para complementar esse processo, faltava um layout adequado às mudanças do periódico. O novo design deveria conseguir captar a ideia de "Uma ponte para o futuro", como Potter a concebia, sobre a qual a humanidade passa, com suas mudanças e transcendências. Segundo Bohnemberger ${ }^{1}$, a ideia de Potter é o símbolo da união entre as humanidades e a área científica tecnológica, repensando o desenvolvimento científico, o meio ambiente, os seres humanos e o mundo que restará para as próximas gerações ${ }^{2}$. Sugere uma aproximação teórica com o pensamento de Edgar Morin ${ }^{3}$ e sua preocupação com a educação para o futuro, que deve ser transformadora, tendo como centro a ética na diversidade cultural e privilegiando a construção de um conhecimento transdisciplinar, que abrange indivíduos, natureza e sociedade.

Ainda segundo Morin ${ }^{3}$, é preciso pensar a ciência com discernimento, posto que ela cria meios poderosos de transformação, manipulação e destruição, ameaçando o meio ambiente e os seres humanos que nele habitam. É necessário implementar novos e elevados padrões de ética e integridade na ciência em geral, e na pesquisa em particular, de modo que o cientista do futuro atue sempre com pleno entendimento das consequências de seu trabalho. Ou seja, a bioética é também a concretização do ideal de que a ciência não é neutra e que deve ser sempre pensada e aplicada para benefício da humanidade, e não para a sua instrumentalização.

Todas as alterações propostas no layout da revista foram coroadas pela inserção do nosso periódico na plataforma internacional Scopus, em março de 2021, sendo a única revista brasileira dedicada ao tema da bioética - publicada em inglês, espanhol e português - a obter esta indexação internacional. A Scopus oferece um panorama abrangente para a produção de pesquisas no mundo, nas áreas de ciência, tecnologia, medicina, ciências sociais, artes e humanidades, sendo um dos referenciais científicos em escala global.

E o número 29.2 da Revista Bioética já se inscreve nessa nova perspectiva de um periódico que tem hoje uma responsabilidade social aumentada no plano internacional. Por isso, mantendo o mesmo rigor científico, trata de temas da maior relevância ética e social, tal como as consequências da pandemia por covid-19 que segue castigando muitos países, motivando inúmeros estudos e reflexões. O mundo mudou, e isso exige que compreendamos as adaptações e flexibilizações em vários aspectos sociais. Neste número é abordado o tema covid-19 e ageísmo: ética da distribuição de recursos em saúde - reflexão essencial na sociedade desenvolvida, em que certos valores trazem à tona a discriminação de determinados grupos sociais, ferindo os princípios da dignidade humana e da justiça. Devido à repercussão desses discursos preconceituosos em relação ao envelhecimento, fica ainda mais importante a existência de políticas públicas voltadas ao tema, para manter 
uma sociedade com maiores justiça social e solidariedade entre os diversos grupos intergeracionais, respeitando-se a vida e os direitos das pessoas idosas ${ }^{4}$.

Outro artigo discorre sobre a avaliação da construção do saber médico numa crítica ético-política, trazendo comentários sobre o livro "Natural, racional, social: razão médica e racionalidade científica moderna", de Madel Terezinha Luz. São confrontados dois sistemas médicos - o de terapêuticas tradicionais e o de terapias alternativas e complementares -, considerando as particularidades culturais das sociedades e os aspectos de política social, pois ambos podem estar eventualmente integrados, considerando a atuação das ciências sociais na área da saúde ${ }^{5}$.

À medida que as sociedades se desenvolvem e avançam, mais pessoas com deficiência ocupam espaços que antes Ihes eram restritos. A formação acadêmica tem papel importante nisso, e a adequação das universidades para garantir acesso a pessoas com deficiência traz como consequência benéfica maior inserção no mercado de trabalho. Na área da saúde o tema é explicitado pelo ponto de vista dos conflitos bioéticos ${ }^{6}$. A plena integração de pessoas com deficiência, em todos os níveis da sociedade, é hoje um marco incontornável das sociedades civilizadas, mas, para que isso aconteça, é necessária uma conscientização dos cidadãos e o ensino da bioética tem uma responsabilidade muito especial, pois é veículo fundamental para este se alcançar este efeito.

Cuidados paliativos são tema recorrente nos direitos fundamentais, na vida e na morte, sempre preservando a autonomia e a dignidade humana, por envolverem importantes questões bioéticas. Falar de cuidados paliativos implica uma abordagem mais ampla sobre ética e terminalidade da vida, vinculada ao conhecimento de conceitos como ortotanásia, distanásia, mistanásia e seus aspectos legais ${ }^{7}$. Dentro da principiologia bioética estão os princípios de autonomia, beneficência, não maleficência e justiça ${ }^{8}$, que são os norteadores e orientadores de práticas médicas e ações humanas ${ }^{9}$. O objetivo dos cuidados paliativos é promover qualidade de vida aos pacientes e familiares com doenças que possam influir na continuidade do viver e que necessitam de cuidados de uma equipe multidisciplinar. Trata-se, de fato, de uma nova filosofia da medicina, em que o triunfalismo tecnológico do final do século XX abre espaço para uma medicina mais compassiva, centrada no cuidado, na compaixão e no amor ao próximo. São atributos tradicionais da ética médica, que se foram diluindo face aos avanços da ciência e da tecnologia, mas que hoje são reencontrados nos cuidados paliativos.

Finalmente, aborda-se o tema sigilo, anonimato e confidencialidade em doadores de sangue com HIV. No Brasil há um entendimento recente do Supremo Tribunal Federal (STF), modificado pela Ação Direta de Inconstitucionalidade 5.543/DF ${ }^{10}$, de junho de 2020, de que é permitida a doação de sangue por homens que tiveram relações sexuais com outros homens nos 12 meses anteriores à doação. Os parâmetros legais anteriores - Portaria $158 / 2016^{11}$ do Ministério da Saúde e o artigo 25 da Resolução da Diretoria Colegiada da Agência Nacional de Vigilância Sanitária (Anvisa) RDC $34 / 2014^{12}$ - foram considerados inconstitucionais, por serem discriminatórios. E é objetivo central da bioética pensar este problema sempre considerando o respeito ao direito a privacidade individual.

Além desses temas, muitos outros assuntos interessantes são abordados neste número. Tenham todos uma excelente leitura!

Os editores 


\section{Referências}

1. Bohnemberger M. Bioética e interdisciplinaridade. Curitiba: Editora CRV; 2017.

2. Ribeiro CD. "Bioetica global" de Potter: ponte para o futuro ou pinguela para o passado? Diversitates Int J [Internet]. 2019 [acesso 21 maio 2021];(2):1-22. Disponível: https://bit.ly/3wLHhMt

3. Morin E. Os sete saberes necessários à educação do futuro. São Paulo: Cortez; 2011.

4. Silva MF, Silva DSM, Bacurau AGM, Francisco PMSB, Assumpção D, Neri AL, Borim FSA. Ageismo contra idosos no contexto da pandemia da covid-19: uma revisão integrativa. Rev Saúde Pública [Internet]. 2021 [acesso 21 maio 2021];55:4. DOI: 10.11606/s1518-8787.2021055003082

5. Nascimento MC, Barros NF, Nogueira MI, Luz MT. A categoria racionalidade médica e uma nova epistemologia em saúde. Ciênc. saúde coletiva[Internet]. 2013 [acesso 21 maio 2021];18(12):3595-604. DOI: 10.1590/S1413-81232013001200016

6. Murray B. Oportunidades de empleo y de formación para las personas con discapacidad: papel de la OIT. Educación obrera [Internet]. 2004 [acesso 21 maio 2021];137:1-11. Disponível: https://bit.ly/3fzJHrB

7. Liz AM, Murari JCL, Rodrigues HV, Ferreira FF, Capalonga D, Murari AL. A terminalidade da vida e os aspectos bioéticos. Anais do $10^{\circ}$ Salão Internacional de Ensino, Pesquisa e Extensão (Siepe) [Internet]. Universidade Federal do Pampa, Santana do Livramento, 2018 [acesso 21 maio 2021]. Disponível: https://bit.ly/3yOvlpz

8. Moritz RD, Rossini JP, Deicas A. Cuidados paliativos na UTI: definições e aspectos ético-legais. In: Moritz RD. Cuidados paliativos nas unidades de terapia intensiva. São Paulo: Atheneu; 2012. p. 19-32.

9. Koerich MS, Machado RR, Costa E. Ética e bioética: para dar início à reflexão. Texto \& Contexto Enferm [Internet]. 2005 [acesso 21 maio 2021];14(1):106-10. DOI: 10.1590/S0104-07072005000100014

10. Supremo Tribunal Federal. Ação direta de inconstitucionalidade 5.543 Distrito Federal [Internet]. Brasília [acesso 21 maio 2021]. Disponível: https://bit.ly/3pihR6N

11. Brasil. Ministério da Saúde. Portaria No 158, de 4 de fevereiro de 2016. Redefine o regulamento técnico de procedimentos hemoterápicos [Internet]. Brasília [acesso 21 maio 2021]. Disponível: https://bit.ly/3i6QkTW

12. Agência Nacional de Vigilância Sanitária (Anvisa). Resolução da Diretoria Colegiada da Anvisa RDC 34, de 11 de junho de 2014 [Internet]. Brasília [acesso 21 maio 2021]. Disponível: https://bit.ly/3c30tNB 